\title{
Factores clave de éxito en el negocio del retail
}

\author{
David Gerardo Guerrero Martínez \\ Mijares, Angoitia, Cortés y Fuentes, S.C. D.F. México, México \\ Correo electrónico: dguerrero@macf.com.mx
}

Recibido: 29/5/2012 / Aprobado: 2/7/2012

Resumen: El negocio del retail o venta al detalle se ha desarrollado globalmente y percibimos un importante crecimiento en América Latina. Estos retailers son empresas generadoras de mano de obra intensiva y "disparan" el consumo interno en los países; por ello, tienen un impacto importante en el producto bruto per cápita. El éxito de estas empresas está sustentado en una serie de factores que describiremos en este artículo. Sin embargo, no percibimos que las universidades presenten en su currículo cursos específicos o programas de especialización en retail, que no es exclusivamente un negocio de mercadotecnia ni de publicidad. Se trata de un negocio mucho más complejo, que engloba el manejo de la cadena de suministros, la rentabilidad de la inversión, la logística, los aspectos ambientales y jurídicos, etcétera.

Palabras clave: Retail en América Latina / venta al detalle / cadena de suministro / estrategias en los negocios

\section{Key success factors in the retail business}

ABSTRACT: The retail business has grown globally and we see significant growth in Latin America. These retailers are companies that generate labor-intensive activities and they trigger domestic consumption in their countries so they have a significant impact on GDP per capita. The success of these companies is supported by a number of factors described in this article. However, we do not perceive that universities include in their curriculum, specific courses or programs of specialization in retail, which is not exclusively marketing or advertising; it includes activities such as managing the supply chain, return on investment, logistics, environmental and legal aspects, among other branches.

Keywords: Retail in Latin America / retail business / supply chain / business strategies 
Durante los últimos 10 años, el negocio del retail ha crecido sustantivamente en el Perú, convirtiéndose en una fuente muy importante de empleo y un canal de venta fundamental para empresas nacionales y extranjeras. Pero, ¿qué es el retail? Retail es un término inglés usado para definir la venta de productos - al por menor o al detalle- de persona a persona. Este canal de venta al detalle engloba un amplio sector de negocios que va desde supermercados, hipermercados, cadena de farmacias, tiendas de marca, cadena de tiendas de conveniencia y restaurantes, hasta sucursales bancarias. Hoy en día el retail (véase el glosario al final del artículo) también enmarca la venta de mercancías por catálogo e inclusive a las ventas por internet.

Dentro del conocido ranking de empresas norteamericanas, Fortune 100, listado de empresas por sus ingresos por ventas, el 18\% de los ingresos provienen de empresas del sector retail, superándolo solo el sector financiero con el $22 \%$ de los ingresos. La empresa que destaca por excelencia es Walmart, la empresa de mayor ingreso por ventas en Estados Unidos y en el mundo dentro del sector retail. Asimismo, dentro de la lista de las 20 empresas con mayores ventas de retail del mundo, 11 son norteamericanas, 5 alemanas, 2 francesas, 1 japonesa y 1 británica. Solo 5 de estas 20 empresas globales tienen presencia en América Latina: Walmart, Carrefour, Home Depot, Sears y Costco.

Tabla 1

Ranking de los 10 retailers más grandes del mundo (datos al 2005)

\begin{tabular}{clcc}
\hline Ranking & Retailer & País & $\begin{array}{c}\text { Ventas US\$ } \\
\text { (millones) }\end{array}$ \\
\hline 1 & Walmart & EE. UU. & 312.427 \\
2 & Carrefour & Francia & 92.778 \\
3 & Home Depot & EE. UU. & 81.511 \\
4 & Metro AG & Alemania & 69.134 \\
5 & Tesco & Reino Unido & 68.866 \\
6 & Kroger & EE. UU. & 60.553 \\
7 & Target & EE. UU. & 52.620 \\
8 & Costco & EE. UU. & 51.862 \\
9 & Sears & EE. UU. & 49.124 \\
10 & Scharz & Alemania & 45.891 \\
\hline
\end{tabular}

Fuente: Global Powers of Retailing, Stores (enero 2007), pp. 17-18. 
Las cadenas de supermercados — retail de alimentos- continúan dominando el sector. Ocho de las diez empresas más grandes de retail del mundo son de venta de alimentos. Más del 50\% de las 250 empresas de retail más grandes tienen en su formato de venta a supermercados, hipermercados, almacenes y centros de distribución e inclusive cadenas de tiendas de conveniencia. En América Latina destacan empresas de retail como los grupos Pão de Açúcar de Brasil y Cencosud de Chile. El negocio del retail en gran escala aún no ha penetrado sustantivamente en nuestra región, sin embargo, es un canal de venta en expansión, sobre todo los supermercados, definidos por los expertos en mercadotecnia como el canal de venta moderno.

Figura 1

Logotipos de tres empresas de retail en Latinoamérica

Pão de Açúcar-Brasil

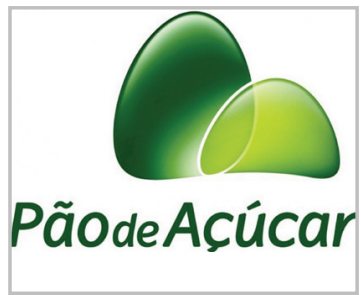

Cencosud-Chile

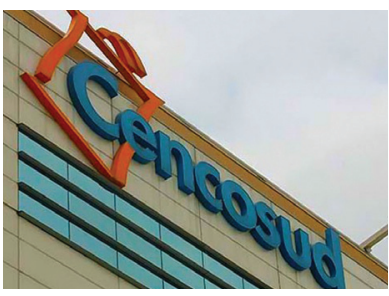

Carrefour-Brasil

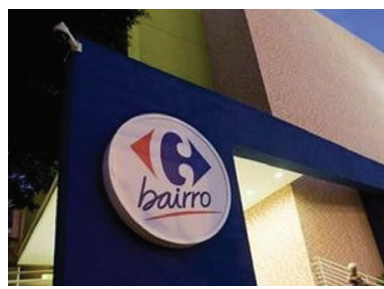

Fuentes: <www.paodeacucar.com.br>.

$<$ www.theclinic.cl $>$.

$<$ www.carrefour.com.br>.

La naturaleza del negocio del retail puede diferir en las diversas regiones del mundo, sobre todo por las cadenas de distribución y el tamaño de las tiendas. Las empresas norteamericanas destacan por manejar grandes centros de distribución y tiendas de gran tamaño - más de 2.000 metros cuadrados- a diferencia de las cadenas de retail en China e India, donde existen múltiples cadenas de tiendas en espacios relativamente pequeños. No hay duda de que el modelo norteamericano es el más eficiente, porque elimina la cadena de mayoreo y hace muy eficiente la cadena de suministro de productos. Las cadenas europeas de retail presentan un modelo intermedio, es decir, entre el modelo norteamericano y el modelo de la China e India.

¿En qué consiste el negocio del retail? La empresa de retail vende productos o servicios a clientes para su uso personal o familiar; son el último eslabón en la cadena de suministros, ya que enlaza a los pro- 
ductores con los clientes. Por lo tanto, la cadena de suministros está compuesta por un grupo de empresas que entregan sus productos o servicios al cliente final. Este es el modelo típico y, en nuestro medio, lo vemos por ejemplo cuando Nestlé coloca sus productos a través de la cadena de supermercados Wong. Sin embargo, existen otros modelos de venta donde el fabricante manufactura sus productos y también tiene sus tiendas de retail. Siguen este modelo empresas como Dell y Apple. Un ejemplo de empresa en nuestro país podría ser la cadena de productos textiles Topitop, que manufactura sus productos y los vende en su propia cadena de tiendas.

Figura 2

Modelo de cadena de suministros

Productor

Mayorista

Retailer

Consumidor
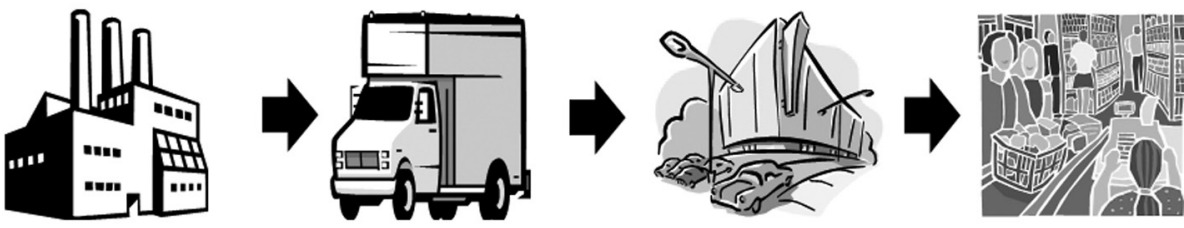

Elaboración propia.

En el Perú estamos acostumbrados al uso del término 'venta mayorista'. Este es un canal también importante, porque se maneja de modo similar al de retail. Los mayoristas compran a los fabricantes importantes cantidades de productos y los revenden a las cadenas de retail o a los usuarios finales (restaurantes, farmacias, entre otros negocios). Algunos negocios tradicionales de mayoreo son la venta y distribución de productos farmacéuticos, golosinas, licores, alimentos, entre otros. Estos mayoristas venden a cadenas de empresas; sin embargo, hay negocios que se han desarrollado de forma tal — por ejemplo el sector de farmacias - que hoy son considerados como cadenas de retail por la diversidad de mercancías que venden en adición a los medicamentos. Solo basta visitar las cadenas de farmacias FASA e Inkafarma para observar que son un canal de venta de múltiples productos para la higiene personal e incluso de refrescos, y cuentan con terminales bancarios ATM o cajeros electrónicos. 


\section{CARACTERÍSTICAS DEL RETAILERO DETALLISTA}

En el país existen miles de retailers o negocios de venta al detalle, desde empresas unipersonales, como el caso de venta al detalle de sánguches en el muy conocido "carrito sanguchero", pasando por cadenas de autoservicio como Wong, Metro, Maestro Home Center, La Curacao, hasta cadenas departamentales como Saga Falabella, Ripley y Zara.

Los retailers de alimentos han cambiado en los últimos 20 años, transformándose de cadenas de supermercados de venta de alimentos en hipermercados con ventas de alimentos y bebidas, vestido y calzado, equipos electrónicos y electrodomésticos, productos de farmacia, servicio de lavandería, entre otros. Un simple vistazo a una tienda de la cadena de hipermercados Metro nos permitirá ver la magnitud del SKU (del inglés stock keeping unit) que manejan estas tiendas. En promedio un hipermercado maneja un rango de 30.000 a 40.000 SKU. Muchos hipermercados también presentan, como parte de sus servicios, restaurantes, cafeterías y bancos. Asimismo, los retailers de alimentos están adoptando las tendencias europeas donde incluyen un nuevo formato de supermercado con productos de tipo gourmet. En estos casos, los consumidores están dispuestos a pagar un mayor precio o precio premium por ciertos productos de tipo aspiracional, como podría ser el aceite de oliva de procedencia italiana marca Roland, el agua envasada Perrier o Pellegrino o las cervezas europeas. También han proliferado las llamadas "tiendas de conveniencia". Estas tiendas manejan menos de 1.000 SKU y tradicionalmente se encuentran en las gasolineras, como el caso de la cadena Primax, donde encontramos golosinas, bebidas gaseosas, productos de higiene personal, entre otros productos. Estos establecimientos presentan cajeros express para una rápida atención. De alguna manera estas cadenas de tiendas de conveniencia han ido reemplazando a las pequeñas tiendas o bodegas de barrio, que en inglés se conocen como las tiendas mom-and-pop.

Las tiendas departamentales han tomado un importante auge dentro del mercado de retail. Estos negocios presentan una gran variedad de productos y servicios y organizan sus tiendas por departamentos para mostrar sus productos, es decir, departamentos de perfumería, muebles, electrodomésticos, calzado de damas y otros más. Por lo general, estas cadenas de tiendas por departamentos están ubicadas en centros o plazas comerciales. El más relevante del país es el Jockey Plaza, donde se encuentran las dos más importantes tiendas depar- 
tamentales del Perú: Saga Falabella y Ripley. Es habitual que en estos centros comerciales se encuentren tiendas de especialidades, como Tommy Hilfiger, Payless Shoes, Zara y Topitop, entre muchas otras. Estos retailers explotan sus diseños de marca, mientras otros, en el ramo de la construcción por ejemplo, presentan una importante variedad de productos para el hogar y la oficina, como el caso de Sodimac, Ace Home Center y Maestro. Es importante resaltar que en el segmento de artículos de oficina en nuestro país destacan los retailers Tai Loy y Librerías Minerva.

En los últimos años las tradicionales farmacias y boticas se han convertido en cadenas de retailers. Desde que se iniciaron las cadenas de farmacias, como la conocida Botica Torres de Limatambo, en el distrito de San Borja, en Lima, hasta cadenas como FASA e Inkafarma, donde se expende una variedad de productos de higiene personal en adición a las líneas de productos farmacéuticos.

En Estados Unidos, estas cadenas de retail venden productos farmacéuticos, una gran variedad de estos sin receta médica, productos de higiene personal y de belleza así como alimentos y bebidas. Casos como CVS Pharmacy y Walgreens son tiendas con una gran presencia en este segmento de mercado.

En el mencionado país están proliferando las conocidas cadenas de "One Dollar Store". Estas son cadenas de tiendas que tienen precios reducidos y fijos en 3 o 4 niveles, como Family Dollar y Dollar General, que tienen un precio de no más de 20 dólares por ticket. Pero también están las tiendas "One Dollar Store" y "99 Cents Only". Estas tiendas venden sus productos efectivamente en menos de un dólar. Otros retailers se focalizan en equipos electrónicos y electrodomésticos, como las conocidas cadenas Radio Shack y Best Buy. En nuestro país se han posicionado en este segmento las cadenas La Curacao, Carsa e Hiraoka.

Es muy habitual que todas estas cadenas de retail realicen una estrategia de comunicación directa a través de varios canales de comunicación. La publicación de los catálogos de Ripley, Falabella, Hiraoka, Wong y Metro es muy conocida y destacada en los medios de comunicación escrita. Estos encartes publicitarios presentan publicidad pagada por los productores y dueños de las marcas, quienes patrocinan el encarte. 
No podemos dejar de mencionar la venta a través de catálogos, es decir la venta directa, que cuenta con fuerzas de ventas como las de Avon y Yanbal, entre otras empresas del ramo de productos de belleza. En los últimos años ha proliferado la venta directa a través de anuncios comerciales por televisión, más conocido como el T-commerce. Estos comerciales de televisión incitan la compra de productos no disponibles en tiendas. Simplemente a través de una llamada telefónica se adquiere esta mercadería con cargo a su tarjeta de crédito.

La venta a través de las llamadas vending machines o máquinas dispensadoras ha crecido sustantivamente. Desde las acostumbradas máquinas que contienen bebidas gaseosas, bebidas calientes y golosinas hasta las de accesorios de celulares, audífonos, auriculares para celulares, entre muchos otros productos. En algunos aeropuertos de Estados Unidos se pueden apreciar estas vending machines, como las que usa la empresa de venta de artículos electrónicos Best Buy.

\section{ESTRATEGIA DE LOS RETAILERS}

\subsection{Mercado objetivo y formato}

Pero, ¿qué ha hecho exitoso el negocio del retailer en estos últimos 20 años? La estrategia que han seguido estos retailers ha sido un factor de éxito. La voraz competencia ha obligado a innovar, redefinir estrategias y usar tecnologías de punta para hacer una planeación estratégica de largo plazo orientada a crecer en su mercado objetivo y maximizar sus utilidades. El concepto del retailing es una orientación gerencial que se concentra en conocer las necesidades de su mercado objetivo y satisfacerlas eficiente y efectivamente. Aún tratándose de un modelo exitoso, el retailer tendrá que definir siempre nuevas estrategias para mantener a sus clientes.

Por ejemplo, si una persona de clase media desea adquirir un perfume y se considera de hábitos tradicionales de compra, seguramente adquirirá el perfume en una cadena de farmacias o en un supermercado. Sin embargo, si esta misma persona sigue las tendencias de moda, es altamente probable que la compra la realice en una tienda por departamentos. Habrá también personas más conservadoras que realizarán sus compras por catálogo; por ello, los retailers deberán buscar los formatos más adecuados. 
La estrategia medular de un retailer es construir una ventaja competitiva sostenible en el tiempo en comparación con otras empresas del ramo. Esto significa que el retail deberá construir una muralla lo suficientemente alta con la finalidad de mantener a sus clientes o ser líder en su mercado objetivo. Es usual que dentro de esta estrategia, los retailers mantengan: a) lealtad del cliente al retailer; b) ubicación idónea al mercado objetivo; 3) equipo gerencial altamente calificado, d) sistemas informáticos de clase mundial; e) productos únicos; f) estrecha colaboración con sus proveedores; y g) servicio al cliente.

Los retailers han crecido sustantivamente por haber sido exitosos en captar un mercado objetivo; sin embargo, aún hay oportunidades de crecimiento, siempre y cuando se focalicen en los siguientes cuatro tipos de oportunidades:

a) La penetración de mercado.- En esta oportunidad, el retailer debe motivar a sus actuales clientes a realizar compras más frecuentes y a visitarlos, siempre manteniendo el mismo formato, es decir, a través de sus actuales establecimientos, lo cual no impide la posibilidad de abrir nuevos locales.

b) Una segunda oportunidad es la expansión de mercados a través del mismo formato pero en segmentos de mercado diferentes.

c) Una tercera oportunidad de crecimiento se da a través del desarrollo de nuevos formatos, es decir, nuevos canales de venta para llegar a su mercado objetivo.

d) Y finalmente, una cuarta oportunidad vinculada con la diversificación. Algunos retailers han ingresado a mercados muy diferentes a su negocio principal u original.

\subsection{Las finanzas del retailer}

Toda estrategia tiene su medición o evaluación financiera. En este caso, los retailers deben descansar en una eficiente y oportuna información financiera que les permita tomar decisiones rápidas y minimizar pérdidas de dinero o posicionamiento de mercado en su segmento de negocio. Una metodología que permite medir el desempeño del retailer es el cálculo del "retorno sobre los activos", más conocido como ROA.

Este modelo presenta dos componentes, el primero es el margen neto de utilidad que genera el negocio y el segundo tiene que ver con la rotación de los activos. En el primero, el margen neto de utilidad 
significa cuánta utilidad después del impuesto a la renta e intereses genera el negocio dividido entre el ingreso por ventas. Es decir, cuánto se genera de utilidad por cada sol que se vende en productos o servicios. En el segundo caso, la rotación de los activos significa cuánto dinero por ventas han generado los activos de la empresa.

\subsection{Ubicación}

Una de las estrategias más importantes que deben definir los retailers es la ubicación geográfica del establecimiento. No hay duda de que la ubicación es la razón más influyente para que un cliente decida en qué tienda realizará su compra.

Asimismo, la ubicación se convierte en una ventaja competitiva por lo que sus competidores deberán copiar la ubicación o tendrán que resignarse a la segunda mejor opción de ubicación. Los retailers enfrentan riesgos al escoger una ubicación debido a que deben arrendar un local o comprar la propiedad. Si hay error al escoger la ubicación, el retailer tendrá que asumir el costo económico de una salida anticipada del contrato o vender la propiedad a un menor valor de aquel al cual lo adquirió.

Lo primero que debe medir un retailer es la condición socioeconómica del lugar donde desea ubicarse o, en muchos casos, la ubicación tiene que ver con las características del flujo de tráfico y accesibilidad al establecimiento. En segundo lugar, el retailer tendrá que lidiar con los costos operativos de la tienda. Tiendas de marcas Premium en centros comerciales son típicamente sustentables en el tiempo.

\subsection{Recursos humanos}

Los retailers, para alcanzar sus objetivos de rentabilidad, deben mantener un perfecto balance de 5 activos críticos: a) ubicación; b) inventario de mercadería; c) tiendas; d) empleados; y e) clientes. Una de las mayores ventajas competitivas que un retailer puede construir es a través de su capital humano. El costo de la mano de obra es el más relevante en la estructura de costos del retailer, por lo que administrar ese capital humano tiene un rol trascendental en el éxito de la organización. El proceso de comprar en una tienda puede ser tanto una experiencia gratificante como la más nefasta. Esto puede deberse al nivel de experiencia del personal que trata con los clientes. El conocimiento por 
parte del vendedor sobre el producto y su disponibilidad, la apariencia física o presentación del vendedor, la actitud de servicio, entre otras competencias del personal, pueden lograr que el retailer se posicione en el mercado objetivo. Las grandes cadenas de retailers cuentan con una organización de recursos humanos altamente calificados que permite una selección de personal adecuada, procesos de capacitación continua, evaluación del desempeño y desarrollo de planes de carrera. En un mercado altamente competitivo, es importante mantener el talento motivado con incentivos para la obtención de objetivos, al igual que un diseño de un plan de carrera y promoción que permita al empleado mantener la lealtad con su empleador, porque considera a su empresa como un buen lugar para trabajar y desarrollarse profesionalmente.

\subsection{Sistemas de información}

La tecnología de la información se ha convertido en la más importante herramienta con que debe contar el retailer para ser más eficiente, reducir costos, elevar el nivel de servicio al cliente y, sobre todo, contar con valiosa información del mercado y sus finanzas, esto, como una ventaja competitiva. Los sistemas usados para controlar el flujo de información que necesita el personal de compras del retailer y la información hacia los proveedores se han vuelto tecnologías sofisticadas. Hoy en día los principales retailers cuentan con un alto volumen de información del cliente sobre sus preferencias de compra. Esta información es usada para reforzar la relación del retailer con el cliente y así mejorar la productividad de su mercadotecnia y un mejor manejo de sus inventarios.

La mayoría de retailers cuentan con sistemas contables financieros automatizados (Enterprise Resource Planning - ERP) que les permite consolidar su información contable en un solo repositorio de información. La adopción de procesos contables de clase mundial le permitirá al retailer contar con información veraz y oportuna, de esa manera, podrá demostrar un eficiente gobierno corporativo y estará en capacidad de acceder a fuentes de financiamiento de capital.

\section{SURTIDO DE LAS MERCANCÍAS}

Uno de los procesos más relevantes en retail es el surtido de las mercancías, actividad realizada por los encargados de las compras del retailer. Los compradores manejan inventarios de mercancías que pien- 
san que serán del agrado de los clientes. Aun cuando los compradores participan en ferias de productos, lanzamientos de productos, reciben catálogos, visitan páginas de internet, siguen las tendencias de otras regiones del mundo u otras actividades; ellos pueden cometer errores en las cantidades que adquieren y en la variedad de productos que compran. Por lo tanto, tendrán que deshacerse de estos productos a través de campañas y ofertas para recuperar la inversión y nuevamente volver al ciclo de compras. El proceso de merchandise es el proceso de vender mercancías en cantidades adecuadas, en el lugar correcto, en el momento correcto y así alcanzar los objetivos financieros de la empresa. Los compradores necesitan estar en contacto con los clientes y anticiparse a lo que los clientes quieren comprar. Por lo tanto, los compradores deben tener el olfato muy desarrollado para poder apreciar las tendencias del mercado, pero también la habilidad de analizar las ventas continuamente y tomar las decisiones adecuadas sobre los niveles de inventarios y precios.

El retailer debe evaluar el desempeño del comprador. La gerencia de compras también debe evaluar el retorno del margen bruto sobre el inventario invertido (RMBI). Este ratio RMBI, al igual que el ROA, combina el porcentaje del margen bruto y el ratio venta a inventario, que es el coeficiente de dividir las ventas netas de un producto entre el costo promedio del inventario de dicho producto. De la misma manera que el ratio financiero ROI (retorno de la inversión) es usado en finanzas para interpretar el retorno del capital invertido, el GMBI (retorno del margen bruto sobre el inventario invertido) determina el uso eficiente del inventario invertido y la rentabilidad que le genera al retail. Los retailers quieren obtener el mayor ratio posible de rotación del inventario, sin embargo, deben cuidar que esta alta rotación no impacte negativamente en el margen de la mercancía.

\subsection{Pronóstico de ventas}

Las mercancías siguen un típico patrón: empiezan con niveles bajos, luego se incrementan, alcanzan un punto de estancamiento o madurez y luego declinan. Esto es conocido como el ciclo de vida de la categoría. Conociendo en qué etapa del ciclo de vida se encuentra el producto, se podrá realizar una estimación más confiable del pronóstico de ventas y la estrategia de mercadear el producto. Pronosticar mercancías en categorías de moda es una tarea compleja, pues muchos de los artículos que se ofrecen son nuevos y diferentes de las mercancías ofrecidas en 
temporadas pasadas. En consecuencia, los retailers deben desarrollar pronósticos para estas categorías; por ello, deberán analizar datos de ventas pasadas, su propia intuición o sentido de negocio, experiencia sobre las modas y tendencias, la opinión de los fabricantes y los tradicionales estudios de mercado.

\subsection{Nivel de inventario y disponibilidad de productos}

Los planes de surtido de producto típicamente incluyen los niveles deseados de inventario por cada SKU que serán almacenados en la bodega de la tienda. Esto es conocido como el plan de stock de producto. Mantener un producto en reserva es conocido como mantener un buffer o "colchón" para que el producto no se quede fuera de stock en caso de que la demanda del producto sea importante. Los retailers deben tener especial cuidado en la selección del monto de buffer de producto y debe ser un factor crítico de éxito en la planeación del surtido de productos.

Si el buffer es muy bajo, el retailer corre el riesgo de perder ventas y posiblemente clientes. Hay una serie de factores que los retailers deben contemplar para determinar el nivel de buffer de stock y la disponibilidad de producto por categoría de SKU. Ellos deben considerar la variabilidad de la demanda, los tiempos de entrega del fabricante y la frecuencia de surtido de los productos desde sus almacenes centrales o centros de distribución a las tiendas, con la finalidad de determinar las cantidades de productos que deben comprar.

En la mayoría de los casos, los retailers se aseguran de contar con un stock de buffer de tal manera que no tengan faltantes en stock de ciertas marcas, tallas, colores, etcétera. Para aquellos productos de gran demanda, es altamente necesario contar con estos buffer de stock para satisfacer a los clientes y no mostrarle una mala imagen. Por lo tanto, los retailer deben manejar el lead time o tiempo de entrega del fabricante de forma eficiente para poder efectuar las compras y la reposición de productos cuando estos se agoten.

\section{CONSIDERACIÓN PARA DETERMINAR EL PRECIO}

La determinación del precio es una tarea muy importante en los retailers. Los clientes cuentan con más alternativas para elegir y, sobre todo con mayor información del mercado. Por eso los clientes esperan conseguir el mejor valor por su dinero, valor que en realidad es un ratio 
entre el beneficio percibido por la compra del producto o servicio y el precio pagado. Los retailers pueden incrementar el valor de sus productos y servicios estimulando mayores niveles de ventas, aumentando los beneficios hacia sus clientes o reduciendo el precio de estos. Puede darse el caso que algunos clientes solo deseen pagar el menor precio posible y la percepción de que algún beneficio no sea importante; sin embargo, hay otros clientes que sí están dispuestos a pagar un mayor precio, siempre y cuando sientan que obtienen calidad y servicio.

Es usual que cuando el precio de los productos se incrementa, las ventas decrezcan debido a que los clientes experimentan una sensación de que el producto ya no es de buen valor. Esa sensibilidad al precio determina cuántas unidades del producto se venderán a diferentes niveles de precio. Si los clientes de un mercado objetivo son sensibles al precio, las ventas decrecerán cuando los precios suban. Sin embargo, si los clientes no lo son, las ventas no decrecerán.Ejemplos de ello serían los productos denominados Premium, como las carteras Louis Vuitton, los relojes Rolex, entre otros mútiples casos.

Muchos retailers usan el valor sugerido por el productor para fijar sus precios, pero otros los determinan incrementando un porcentaje sobre el costo del producto para obtener un mejor margen de utilidad, lo que se conoce como mark-up. El mark-up que cobra el retailer sirve para cubrir sus costos fijos por ofrecer los productos (sueldos, renta, publicidad, etcétera) y generarle utilidades al retailer. Algunos retailers, como parte de su estrategia de ventas, pueden vender por debajo del costo con la finalidad de generar un tráfico de clientes en sus tiendas y motivar la compra de otros artículos, en donde recuperarán esa pérdida. También puede variar el precio inicial del producto a lo largo del tiempo o de la estación. Estas reducciones de precio, comúnmente llamadas promociones, incentivarán a los clientes a comprar estos saldos de inventario, por lo que al final del ciclo de negocio el mark-up se reducirá.

Igualmente, los retailers suelen desear conocer el número de unidades que requieren vender para obtener utilidades; por lo tanto, necesitan conocer: a) el punto de equilibrio en ingreso por ventas para obtener utilidades; b) el punto de equilibrio en soles y unidades que justifique la introducción de un producto nuevo; y c) el punto de equilibrio en ingreso por ventas que permita cubrir cualquier cambio en el precio del producto. Las reducciones de precios a través de descuentos son también conocidos como markdown. Los retailers planifican sus 
estrategias para evitar estos descuentos; sin embargo, a veces son inevitables. Los retailers, en muchas ocasiones, liquidan las mercancías al final de una estación de la siguiente manera: venden la mercadería a otros retailers, consolidan la mercadería no vendida y hacen uso de los llamados outlets para colocar sus productos y venderlos a precios reducidos, efectúan la venta a través de internet, donan la mercancía o simplemente la mantienen hasta la siguiente estación.

\section{FUTURO DEL RETAIL EN EL PERÚ}

El incremento del poder de compra de la clase media y el crecimiento económico de las ciudades son los principales factores de éxito del retail en el Perú. Las empresas de retail son generadoras de trabajo tanto calificado como no calificado. También permiten el crecimiento de nuevos emprendedores o de pymes que ofrecen sus productos y servicios a estas cadenas de retail. La expansión del retail fuera de Lima impactará positivamente en el desarrollo de nuevos centros de distribución para surtir productos de una manera más eficiente a las tiendas. Sin embargo, uno de los mayores riesgos para el retail descentralizado es la inseguridad en las carreteras del país. Esta situación puede desincentivar la inversión en el interior del país; por ello, las autoridades de seguridad deben tomar cartas en el asunto a fin de trabajar con la empresa privada en la mejora de los sistemas de seguridad. También debe acompañar esta expansión del retail una legislación ambiental acorde con los tiempos modernos, desde las autorizaciones para la construcción de centros comerciales y tiendas departamentales hasta el manejo de los residuos y desechos de basura de estas empresas.

Un factor de éxito del retail es la mejora en el nivel educativo de los profesionales. El retail no es un área de negocio relacionado exclusivamente con la mercadotecnia, la moda, la publicidad, la construcción de los establecimientos — centros comerciales, restaurantes, etcétera- o al acondicionamiento de las tiendas. El retail necesita profesionales especializados en el manejo de la cadena de suministros, conocimientos de logística (compras), distribución, finanzas y, en especial, tecnología de la información. En los países desarrollados existen programas educativos orientados a la enseñanza del mundo del retail.

En la medida en que exista un mayor dinamismo en la economía peruana y en la confianza del inversionista interno y externo en la Bolsa de Valores peruana, posiblemente veamos financiar la expan- 
sión o el crecimiento del negocio del retail a través de emisiones de papeles de deuda y, por qué no, a través de colocaciones de acciones, para incrementar el capital de la empresa, como sucede en otros países de la región latinoamericana. En algunos de ellos se ha impulsado el crecimiento del negocio del retail a través del crédito al consumo por medio del uso de tarjetas de crédito bancarias o de los mismos retailers. En muchos casos, estos otorgan crédito al consumo con tasa de $0 \%$ de interés y a períodos de 12 a 24 meses, como sucede en México.

Aún falta la entrada de muchos grandes retailers globales y de la región de América Latina a nuestro país, como podría ser Wal-mart o alguno de sus formatos de tiendas, como los price clubs con la cadena Sam's. Otros casos incluyen el retailer más importante de equipos electrónicos, electrodomésticos y tecnológicos, como Best Buy; los retailers de equipos de oficina, como Office Depot y Office Max, y muchas otras cadenas de tiendas departamentales como JC Penny, Sears, Home Depot, etcétera. Lo que sí podemos notar es que ya están apareciendo algunas cadenas de franquicias como las de frozen yogurts, lavanderías, ropas de marcas, entre otras, que ayudarán a la mejora de la economía de las familias y del país. Actualmente, hay un proceso de expansión y consolidación de los retailers en la región, entre ellas destacan, la posible compra de la cadena Pão de Açúcar por parte de la cadena francesa Carrefour, la reciente venta de Farmacias Fasa Perú a un grupo local, y la inminente presencia de Falabella en México.

No podemos dejar de mencionar a la cadena de restaurantes "Astrid y Gastón”, que es posiblemente el más importante retailer peruano fuera de nuestro país.

\section{REFERENCIAS}

1. Baltzan, P., Phillips, A. (2009). Business Driven Technology. Nueva York: McGraw-Hill.

2. Chopra, S. \& Meindl, P. (2007). Administración de la cadena de suministro. México: Parson Prentice Hall.

3. Levy, M. \& Barton, A. (2009). Retailing management. Boston: McGraw-Hill Irwin.

4. Stanton, W., Etzel, M. \& Bruce, W. (2007). Fundamentos de marketing. México: McGraw-Hill. 


\section{GLOSARIO}

ATM: Máquinas dispensadoras de efectivo, más conocidas como cajeros electrónicos.

Cajeros express: Cajas rápidas para evitar que se formen largas colas de gente en los cajeros de tiendas de conveniencia y retailers.

Club de precios: Empresas que combinan la venta al detalle y al mayoreo y cuentan con un surtido muy amplio de productos. Sus precios son bajos pero con pocos servicios. Solo pueden ingresar a las tiendas socios de la empresa.

Fortune 100: Es un listado publicado de forma anual por la revista Fortune, enumerando las 100 mayores empresas norteamericanas de capital abierto según su volumen de ventas.

Gourmet: Productos premium o selectos para paladares exigentes.

Internet: Red global de redes que enlaza a millones de usuarios, creada originalmente para enlazar comunicaciones entre entidades de seguridad del gobierno de Estados Unidos.

Lead time: Tiempo que transcurre desde el momento en que se reconoce la necesidad de poner una orden de compra por algún artículo hasta su llegada al almacén.

Mark-down: Reducción de precio o descuento sobre el precio original de venta.

Mark-up: Incremento del precio de venta de un artículo sugerido por el fabricante. Cubre los costos fijos del retailer.

Merchandise: Proceso por el cual el retailer ofrece a los clientes la cantidad óptima y en el momento adecuado de sus productos y obtiene la utilidad deseada por la empresa.

Outlets: Tiendas de propiedad de retailers o de fabricantes donde venden excedentes de mercancías fuera de temporada a precios reducidos.

Retail: Tipo de negocio que vende al detalle a personas a través de diversos formatos o canales de ventas.

Retailing: Proceso que siguen los retailers de vender a sus clientes en diferentes canales de venta. 
ROA: Viene del término inglés 'return on assets' o retorno sobre los activos.

SKU: Viene del término inglés stock keeping unit. Significa la mínima unidad que debe mantenerse en inventario.

T-commerce: Formato moderno de retail, donde los clientes efectúan sus compras basadas en la publicidad durante el tiempo que ven programas de televisión. Los pagos se efectúan con cargo a la tarjeta de crédito.

Tienda de conveniencia: Empresa de venta al detalle que se concentra en comestibles y no comestibles orientados a prestar un servicio de comodidad. Suele tener precios más altos que los supermercados y ofrece pocos servicios al cliente.

Vending machines: Formato de punto de venta donde se mantienen productos y servicios. Los clientes se surten de los productos usando efectivo o tarjetas de crédito. 